\title{
Asaia (Rhodospirillales: Acetobacteraceae) and Serratia (Enterobacterales: Yersiniaceae) associated with Nyssorhynchus braziliensis and Nyssorhynchus darlingi (Diptera: Culicidae)
}

\author{
Tatiane M. P. Oliveira ${ }^{*}$ (), Sabri S. Sanabani², Maria Anice M. Sallum ${ }^{1}$ \\ ${ }^{1}$ Universidade de São Paulo, Faculdade de Saúde Pública, Departamento de Epidemiologia, São Paulo, SP, Brasil. \\ ${ }^{2}$ Universidade de São Paulo, Faculdade de Medicina da São Paulo (FMUSP), Hospital das Clínicas (HCFMUSP), Brasil.
}

\section{A R T I C L E I N F O}

\section{Article history:}

Received 24 October 2019

Accepted 23 April 2020

Available online 08 June 2020

Associate Editor: Mário Navarro-Silva

\section{Keywords:}

Vectors

Malaria

Amazon

\begin{abstract}
A B S T R A C T
Midgut transgenic bacteria can be used to express and deliver anti-parasite molecules in malaria vector mosquitoes to reduce transmission. Hence, it is necessary to know the symbiotic bacteria of the microbiota of the midgut to identify those that can be used to interfering in the vector competence of a target mosquito population. The bacterial communities associated with the abdomen of Nyssorhynchus braziliensis (Chagas) (Diptera: Culicidae) and Nyssorhynchus darlingi (Root) (Diptera: Culicidae) were identified using Illumina NGS sequencing of the V4 region of the 16S rRNA gene. Wild females were collected in rural and periurban communities in the Brazilian Amazon. Proteobacteria was the most abundant group identified in both species. Asaia(Rhodospirillales: Acetobacteraceae) and Serratia (Enterobacterales: Yersiniaceae) were detected in Ny. braziliensis for the first time and its presence was confirmed in Ny. darlingi.
\end{abstract}

Although the malaria burden has decreased worldwide, the disease still imposes enormous suffering for human populations in the majority of endemic countries. Also, the disease continuously threatens the public health, and have a negative impact on the socioeconomic growth of poor communities (Gallup and Sachs, 2001; Shretta et al., 2017). In addition, a recent study by Haakenstad et al. (2019) demonstrated that in 2016, US\$ 4.3 billion was spent on malaria worldwide, and that will reach US\$ 6.6 billion annually in 2020. Although the intensive worldwide controlling effort, sustaining achievement in malaria control will require an enormous effort from endemic countries, and international funding support for the programs (Shretta et al., 2017; Haakenstad et al., 2019).

Currently, the main pillars for malaria control rely on the commodities targeting anopheline vector species, and the detection and treatment of Plasmodium spp. human infection (Baird, 2017; Shretta et al., 2017). However, increasing resistance to artemisinin combination therapies (ACTs) threatens Plasmodium falciparum Welch malaria control (Menard and Dondorp, 2017). Controlling strategies targeting Anophelinae vector species are primarily focused on decreasing human exposure to mosquito

\footnotetext{
* Corresponding author:

Email: porangaba@usp.br (Tatiane M. P. Oliveira).
}

bites by the use of insecticide-treated bed nets, and insecticide indoor residual spraying (Baird, 2017; Shretta et al., 2017; WHO, 2018). The effectivity of vector control technologies is threatened by the emergence of mosquito resistance to insecticides (Baird, 2017).

New technological commodities, such as the genetic manipulation of organisms (Bilgo et al., 2018), are being developed for controlling vector-borne diseases. The employment of transgenic bacteria from the adult mosquito midgut is a potential tool to be employed for decreasing vector competence and vectorial capacity of vector species involved in a pathogen transmission (Villegas and Pimenta, 2014; Kotnis and Kuri, 2016). The symbiotic bacteria (Damiani et al., 2010), viruses (Ren et al., 2008), and fungi (Fang et al., 2011), which are present in a large array of mosquito species, are potential tools for blocking a pathogen dispersion into a mosquito. In this context, the paratransgenesis of microbial organisms by genetically manipulating the insect endosymbiotic bacteria is a promising approach (Durvasula et al., 1997; Wang and Jacobs-Lorena, 2013; Bilgo et al., 2018). Among the symbiotic bacteria found in anopheline vector species, the Asaia (Rhodospirillales: Acetobacteraceae), Pantoea (Enterobacterales: Erwiniaceae), Serratia (Enterobacterales: Yersiniaceae), Pseudomonas (Pseudomonadales: Pseudomonadaceae) and Thorsellia (Enterobacterales: Thorselliaceae) 
bacteria are candidates for paratransgenesis (Villegas and Pimenta, 2014; Mancini et al., 2016; Raharimalala et al., 2016).

Asaia bacteria was found in field-collected specimens of Anopheles stephensi Liston, Anopheles gambiae Giles, Anopheles funestus Giles, Anopheles coustani Laveran, Anopheles maculipennis Meigen, Anopheles superpictus Grassi, Anopheles fluviatilis James, Anopheles dthali Patton, Aedes albopictus (Skuse), Aedes aegypti(Linnaeus), species of the Culex pipiens complex (Favia et al., 2007; Crotti et al., 2009; Manguin et al., 2013; Rami et al., 2018), and recently in Nyssorhynchus darlingi(Root) (Alonso et al., 2019). Species of the Asaia can colonize mosquito salivary gland, midgut, and male and female reproductive apparatus (Favia et al., 2007). Bacteria of the genus Serratia can be employed for malaria control (Koosha et al., 2018). The genetically modified AS1 isolate of the Serratia was able to inhibit the development of P. falciparum in An. gambiae through the secretion of anti-Plasmodium protein molecules. Currently, the Serratia was found in Anopheles albimanus Wiedemann (Gonzalez-Ceron et al., 2003), Anopheles stephensi (Rani et al., 2009), and Ny. darlingi (Arruda et al., 2017).

Recent findings clearly show the importance of mosquito microbiota and the potential of the organisms to reduce the vector competence of a mosquito population by interfering in the sexual life cycle of $P$. falciparum and Plasmodium vivax Grassi and Feletti (Gonzalez-Ceron et al., 2003; Cirimotich et al., 2011). However, the bacterial diversity of the microbiota of a few species has been investigated. Additional studies can provide important information regarding microbiota of primary and secondary Anophelinae species, including those of the Neotropical Region (Terenius et al., 2008; Arruda et al., 2017; Bascuñán et al., 2018; Alonso et al., 2019). This study aims to provide further information about the bacteria associated with the abdomen of field-collected females of Nyssorhynchus darlingi, the primary vector, and Ny. braziliensis (Chagas), the secondary vector species involved in the malaria transmission cycle in the Amazon river basin.

Mosquito female of $\mathrm{Ny}$. braziliensis was collected in the municipality of Humaitá (-63.285549, -7.887513; Amazonas State) in July of 2016, and Ny. darlingi was collected in Cruzeiro do Sul (-72.688722, -7.631889; Acre State) in April of 2015. Mosquitoes were killed with ethyl acetate $\left(\mathrm{C}_{4} \mathrm{H}_{8} \mathrm{O}_{2}\right)$ and immediately preserved in silica gel until species identification by morphological characteristics. After identification, females were preserved at $-80{ }^{\circ} \mathrm{C}$. Females were bisected in the head/thorax and abdomen. DNA extractions were performed at different times. Genomic DNA of the abdomen of the female of $N y$. braziliensis was extracted employing Laporta et al. (2015) protocol. The PowerSoil DNA kit (MO BIO Laboratories, Carlsbad, CA, USA) was employed for DNA extraction of $\mathrm{Ny}$. darlingi abdomen, following the manufacturer's instructions.

The V4 hypervariable region of the 16S rRNA gene was amplified according to Caporaso et al. (2011). Sequencing was performed on the MiSeq platform (Illumina, San Diego, CA, EUA) with MiSeq Reagent Kit v2 (300 cycles), according to the manufacturer's instructions. The PANDAseq v.2.9 software (Masella et al., 2012) was used to assemble the forward and reverse reads using default parameters. The UCHIME algorithm (Edgar et al., 2011) was employed to detect and remove any recombinant sequences from the Illumina sequence data. A minimum of $97 \%$ cutoff of sequence similarity identity was used to define the taxonomic classification of each read. The EzBioCloud (Yoon et al., 2017), with the Mothur algorithm, was used to calculate the diversity indices of bacterial communities, whereas the Shannon diversity index was employed to characterize species diversity in the Illumina sequence data set.

The abdomen of forty-seven anopheline females were sequenced to obtain information of the $\mathrm{V} 4$ region of the $16 \mathrm{~S}$ rRNA gene (unpublished data). In the current study, the microbiota associated with the abdomen of two females is reported. After quality filtering, 56,467 reads were

clustered into OTUs at $97 \%$ similarity threshold. The results from the rarefaction curve analysis showed that the sequencing depth adopted was adequate to detect all bacteria OTUs in both female specimens. Fifty-nine genera of eight phyla were identified in $\mathrm{Ny}$. braziliensis and 83 genera of six phyla were detected in Ny.darlingi. Proteobacteria was the phylum dominant in all samples (Table 1). At the genus level, Escherichia (Enterobacterales: Enterobacteriaceae) was the dominant group in the abdomen of $\mathrm{Ny}$. braziliensis and Ny. darlingi (Fig. 1). Escherichia and Enterobacteriaceae_uc (Enterobacterales: Enterobacteriaceae) were the most abundant genera detected in Ny. braziliensis. The value of the Shannon diversity index was 3.14 for $N y$. braziliensis and 3.96 for Ny. darlingi.

Our results revealed a low relative abundance of the genera Asaia (0.03\%) and Serratia (0.09\%) in Ny. braziliensis, whereas in Ny. darlingiboth genera were found in higher abundance (Asaia - 3.35\%, Serratia-1.02\%). The presence of Asaia and Serratia has been previously reported in $\mathrm{Ny}$. darlingi (Arruda et al., 2017; Alonso et al., 2019), whereas they were identified in $\mathrm{Ny}$. braziliensis for the first time. The presence of bacteria in other Anopheline species (Gonzalez-Ceron et al., 2003; Lindh et al., 2005; Favia et al., 2007; Rani et al., 2009; Manguin et al., 2013; Arruda et al., 2017; Rami et al., 2018) show that they are capable of colonizing a wide range of mosquito because they share stable symbiotic relationship with these vector species. However, further investigations will be necessary to fill gaps in knowledge of the relationships between mosquito species

Table 1.

Number of reads of each phylum in Nyssorhynchus braziliensis and Nyssorhynchus darlingi.

\begin{tabular}{lcc}
\hline \multicolumn{1}{c}{ Phylum } & $\begin{array}{c}\text { Nyssorhynchus } \\
\text { braziliensis }\end{array}$ & Nyssorhynchus darlingi \\
\hline Acidobacteria & 47 & 0 \\
Actinobacteria & 105 & 47 \\
Bacteroidetes & 12 & 80 \\
Cyanobacteria & 26 & 754 \\
Deinococcus-Thermus & 30 & 0 \\
Firmicutes & 189 & 312 \\
Gemmatimonadetes & 23 & 0 \\
Proteobacteria & 47699 & 7123 \\
Verrucomicrobia & 0 & 20 \\
\hline
\end{tabular}

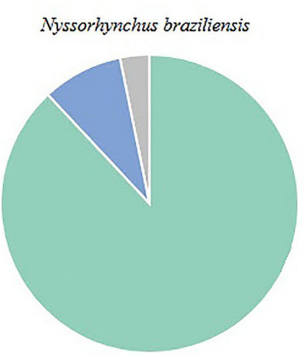

Escherichia (88.05\%)

Enterobacteriaceae_uc $(8.76 \%)$

ETC $[<1.0](3.16 \%)$

Unclassified in higher taxonomic rank $(0.03 \%)$

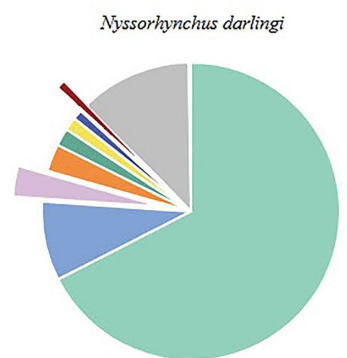

Escherichia $(67.48 \%)$
Enterobacteriaceae_uc (8.59\%)
Asaia $(3.35 \%)$
Symploca_fuc $(2.93 \%)$
Pseudanabaena $(1.93 \%)$
Pseudomonas $(1.44 \%)$
Xantomonas $(1.04 \%)$
Serratia $(1.02 \%)$
ETC $[<1.0](11.96 \%)$
Unclassified in higher taxonomic rank $(0.26 \%)$

Figure 1. Composition of bacteria from the abdomen of Nyssorhynchus braziliensis and Nyssorhynchus darlingi. Only genera that had a relative abundance of $1 \%$ or greater are presented. 
and their associated symbiotic bacteria before these organisms can be employed for a paratransgenic approach to control vector-borne diseases. Genetically manipulated bacteria can be employed for a distinct approach, i.e., to interfere with mosquito reproduction, and oogenesis and embryogenesis processes. In addition, they can be manipulated to express effector molecules to reduce vector competence or cause pathogenic effect in a mosquito population as discussed by Wilke and Marrelli (2015), including Neotropical vector species.

\section{Acknowledgments}

Financial support from Fundação de Amparo à Pesquisa do Estado de São Paulo (FAPESP) grant no. 2014/26229-7 to MAMS; Conselho Nacional de Pesquisa-CNPq no. 301877/2016-5 to MAMS.

\section{Data Statement}

Sequencing data generated for this study have been deposited in the European Nucleotide Archive (ENA; http://www.ebi.ac.uk/ena/) (Project: PRJEB32570, Access numbers: ERS3411567 and ERS3411575).

\section{Conflicts of Interest}

The authors declare no conflicts of interest.

\section{References}

Alonso, D. P., Mancini, M. V., Damiani, C., Cappelli, A., Ricci, I., Alvarez, M. V. N., Bandi, C., Ribolla, P. E. M., Favia, G., 2019. Genome reduction in the mosquito symbiont Asaia. Genome Biol. Evol. 11 (1), 1-10.

Arruda, A., Ferreira, G. S., Lima, N. C. D., Santos Júnior, A. D., Custódio, M. G. F., Benevides-Matos, N., Ozaki, L. S., Stabeli, R. G., Silva, A. A. A., 2017. A simple methodology to collect culturable bacteria from feces of Anopheles darlingi (Diptera: culicidae). J. Microbiol. Methods 141, 115-117.

Baird, J. K., 2017. Malaria control by commodities without practical malariology. BMC Public Health 17 (1), 590.

Bascuñán, P., Niño-Garcia, J. P., Galeano-Castañeda, Y., Serre, D., Correa, M. M., 2018. Factors shaping the gut bacterial community assembly in two main Colombian malaria vectors. Microbiome 6 (1), 148.

Bilgo, E., Vantaux, A., Sanon, A., Ilboudo, S., Dabiré, R. K., Jacobs-Lorena, M., Diabate, A., 2018. Field assessment of potential sugar feeding stations for disseminating bacteria in a paratransgenic approach to control malaria. Malar. J. 17 (1), 367.

Caporaso, J. G., Lauber, C. L., Walters, W. A., Berg-Lyons, D., Lozupone, C. A., Turnbaugh, P. J., Fierer, N., Knight, R., 2011. Global patterns of $16 S$ rRNA diversity at a depth of millions of sequences per sample. Proc. Natl. Acad. Sci. USA 108 (Suppl.1), 4516-4522.

Cirimotich, C. M., Dong, Y., Clayton, A. M., Sandiford, S. L., Souza-Neto, J. A., Mulenga, M., Dimopoulos, G., 2011. Natural microbe-mediated refractoriness to Plasmodium infection in Anopheles gambiae. Science 332 (6031), 855-858. PMid:21566196.

Crotti, E., Damiani, C., Pajoro, M., Gonella, E., Rizzi, A., Ricci, I., Negri, I., Scuppa, P., Rossi, P., Ballarini, P., Raddadi, N., Marzorati, M., Sacchi, L., Clementi, E., Genchi, M., Mandrioli, M., Bandi, C., Favia, G., Alma, A., Daffonchio, D., 2009. Asaia, a versatile acetic acid bacterial symbiont, capable of cross-colonizing insects of phylogenetically distant genera and orders. Environ. Microbiol. 11 (12), 3252-3264. PMid:19735280.
Damiani, C., Ricci, I., Crotti, E., Rossi, P., Rizzi, A., Scuppa, P., Capone, A., Ulissi, U., Epis, S., Genchi, M., Sagnon, N., Faye, I., Kang, A., Chouaia, B., Whitehorn, C., Moussa, G. W., Mandrioli, M., Esposito, F., Sacchi, L., Bandi, C., Daffonchio, D., Favia, G., 2010. Mosquito-bacteria symbiosis: the case of Anopheles gambiae and Asaia. Microb. Ecol. 60 (3), 644-654.

Durvasula, R. V., Gumbs, A., Panackal, A., Kruglov, O., Aksoy, S., Merrifield, R. B., Richards, F. F., Beard, C. B., 1997. Prevention of insect-borne disease: an approach using transgenic symbiotic bacteria. Proc. Natl. Acad. Sci. USA 94 (7), 3274-3278.

Edgar, R. C., Haas, B. J., Clemente, J. C., Quince, C., Knight, R., 2011. UCHIME improves sensitivity and speed of chimera detection. Bioinformatics 27 (16), 2194-2200.

Fang, W., Vega-Rodríguez, J., Ghosh, A. K., Jacobs-Lorena, M., Kang, A., St. Leger, R. J., 2011. Development of transgenic fungi that kill human malaria parasites in mosquitoes. Science 331 (6020), 1074-1077.

Favia, G., Ricci, I., Damiani, C., Raddadi, N., Crotti, E., Marzorati, M., Rizzi, A., Urso, R., Brusetti, L., Borin, S., Mora, D., Scuppa, P., Pasqualini, L., Clementi, E., Genchi, M., Corona, S., Negri, I., Grandi, G., Alma, A., Kramer, L., Esposito, F., Bandi, C., Sacchi, L., Daffonchio, D., 2007. Bacteria of the genus Asaia stably associate with Anopheles stephensi, an Asian malarial mosquito vector. Proc. Natl. Acad. Sci. USA 104 (21), 9047-9051. PMid:17502606.

Gallup, J. L., Sachs, J. D., 2001. The economic burden of malaria. Am. J. Trop. Med. Hyg. 64 (1-2, Suppl.), 85-96.

Gonzalez-Ceron, L., Santillan, F., Rodriguez, M. H., Mendez, D., HernandezAvila, J. E., 2003. Bacterial in midguts of field-collected Anopheles albimanus block Plasmodium vivax sporogonic development. J. Med. Entomol. 40 (3), 371-374.

Haakenstad, A., Harle, A. C., Tsakalos, G., Micah, A. E., Tao, T., Anjomshoa, M., Cohen, J., Fullman, N., Hay, S. I., Mestrovic, T., Mohammed, S., Mousavi, S. M., Nixon, M. R., Pigott, D., Tran, K., Murray, C. J. L., Dieleman, J. L., 2019. Tracking spending on malaria by source in 106 countries, 2000-16: an economic modelling study. Lancet Infect. Dis. 19 (7), 703-716. PMid:31036511.

Koosha, M., Vatandoost, H., Karimian, F., Choubdar, N., Oshaghi, M. A., 2018. Delivery of a genetically marked Serratia AS1 to medically important arthropods for use in RNAi and paratransgenic control strategies. Microb. Ecol. 78 (1), 185-194.

Kotnis, B., Kuri, J., 2016. Evaluating the usefulness of paratransgenesis for malaria control. Math. Biosci. 277, 117-125.

Laporta, G. Z., Burattini, M. N., Levy, D., Fukuya, L. A., Oliveira, T. M. P., Maselli, L. M. F., Conn, J. E., Massad, E., Bydlowski, S. P., Sallum, M. A. M., 2015. Plasmodium falciparum in the southeastern Atlantic forest: a challenge to the bromeliad-malaria paradigm? Malar. J. 14, 181.

Lindh, J. M., Terenius, O., Faye, I., 2005. 16S rRNA gene-based identification of midgut bacteria from field-caught Anopheles gambiaesensulato and $A$. funestus mosquitoes reveals new species related to known insect symbionts. Appl. Environ. Microbiol. 71 (11), 7217-7223.

Mancini, M. V., Spaccapelo, R., Damiani, C., Accoti, A., Tallarita, M., Petraglia, E., Rossi, P., Cappelli, A., Capone, A., Peruzzi, G., Valzano, M., Picciolini, M., Diabaté, A., Facchinelli, L., Ricci, I., Favia, G., 2016. Paratransgenesis to control malaria vectors: a semi-field pilot study. Parasit. Vectors 9, 140.

Manguin, S., Ngo, C. T., Tainchum, K., Juntarajumnong, W., Chareonviriyaphap, T., Michon, A. L., Jumas-Bilak, E., 2013. Bacterial biodiversity in midguts of Anopheles mosquitoes, malaria vectors in Southeast Asia In: Manguin S, editor. Anopheles Mosquitoes: New Insights Into Malaria Vectors. InTech Open Access, Croatia, pp. 549-576.

Masella, A. P., Bartram, A. K., Truszkowski, J. M., Brown, D. G., Neufeld, J. D., 2012. PANDAseq: paired-end assembler for illumina sequences. BMC Bioinformatics 13, 31.

Menard, D., Dondorp, A., 2017. Antimalarial drug resistance: a threat to malaria elimination. Cold Spring Harb. Perspect. Med. 7 (7), a025619. 
Raharimalala, F. N., Boukraa, S., Bawin, T., Boyer, S., Francis, F., 2016. Molecular detection of six (endo-) symbiotic bacteria in Belgian mosquitoes: first step towards the selection of appropriate paratransgenesis candidates. Parasitol. Res. 115 (4), 1391-1399.

Rami, A., Raz, A., Zakeri, S., Djadid, N. D., 2018. Isolation and identification of Asaia sp. in Anopheles spp. mosquitoes collected from Iranian malaria settings: steps toward applying paratransgenic tools against malaria. Parasit. Vectors 11 (1), 367.

Rani, A., Sharma, A., Rajagopal, R., Adak, T., Bhatnagar, R. K., 2009. Bacterial diversity analysis of larvae and adult midgut microflora using culture-dependent and culture-independent methods in labreared and field-collected Anopheles stephensi: an Asian malarial vector. BMC Microbiol. 9, 96. PMid:19450290.

Ren, X., Hoiczyk, E., Rasgon, J. L., 2008. Viral paratransgenesis in the malaria vector Anopheles gambiae. PLoS Pathog. 4 (8), e1000135. PMid:18725926.

Shretta, R., Zelman, B., Birger, M. L., Haakenstad, A., Singh, L., Liu, Y., Dieleman, J., 2017. Tracking development assistance and government health expenditures for 35 malaria-eliminating countries: 19902017. Malar. J. 16 (1), 251.
Terenius, O., Oliveira, C. D., Pinheiro, W. D., Tadei, W. P., James, A. A., Marinotti, 0., 2008. 16S rRNA gene sequences from bacteria associated with adult Anopheles darlingi (Diptera: Culicidae) mosquitoes). Mosquitoes.J. Med. Entomol. 45 (1), 172-175.

Villegas, L. M., Pimenta, P. F. P., 2014. Metagenomics, paratransgenesis and the Anopheles microbiome: a portrait of the geographical distribution of the anopheline microbiota based on a meta-analysis of reported taxa. Mem. Inst. Oswaldo Cruz 109 (5), 672-684.

Wang, S., Jacobs-Lorena, M., 2013. Genetic approaches to interfere with malaria transmission by vector mosquitoes. Trends Biotechnol. 31 (3), 185-193.

Wilke, A. B. B., Marrelli, M. T., 2015. Paratransgenesis: a promising new strategy for mosquito vector control. Parasit. Vectors 8, 342.

World Health Organization - WHO, 2018. World Malaria Report. WHO, Geneva. Available in: http://www.who.int/malaria/publications/ world-malaria-report-2018/report/en/ (accessed 27 Jan 2019).

Yoon, S. H., Ha, S. M., Kwon, S., Lim, J., Kim, Y., Seo, H., Chun, J., 2017. Introducing EzBioCloud: a taxonomically united database of $16 \mathrm{~S}$ rRNA gene sequences and whole-genome assemblies. Int. J. Syst. Evol. Microbiol. 67 (5), 1613-1617. 